\title{
Kenar Algılama ve Morfoloji Operatörleri Kullanılarak Detay Çıkarımı Üzerine Bir Uygulama
}

\author{
Güzide Miray PERİHANOĞLU ${ }^{1}$, Ufuk ÖZERMAN², Dursun Zafer ŞEKER ${ }^{3}$ \\ ${ }^{1}$ Van Yüzüncü Y1l Üniversitesi, Güvenlik Meslek Yüksekokulu, Mülkiyet Koruma Bölümü, Van \\ (gm.perihanoglu@yyu.edu.tr) ORCID ID 0000 - 0002 -2730-590X \\ ${ }^{2}$ İstanbul Teknik Üniversitesi, İnşaat Fakültesi, Geomatik Mühendisliği Bölümü, İstanbul \\ (ozerman, seker@itu.edu.tr) ORCID ID 0000 - 0001 - 9812 - 2185, ORCID ID 0000 - 0001 - 7498 - 1540
}

$\ddot{O} \mathbf{z}$

Bilgisayar teknolojisindeki gelişmelere paralel olarak dijital görüntü işleme yöntemleri yersel fotogrametri çalışmalarında farklı ve geniş uygulama alanları bulmuştur. Yersel fotogrametri uygulamaları; tarihi eserlere ait görüntülerin iyileştirilmesi ve zenginleştirilmesi, kültürel mirasın korunması, belgelenmesi ve gelecek nesillere sağlıklı bir şekilde aktarılabilmesi açısından önem taşımaktadır. Bu çalışmada, dijital görüntü işleme teknikleri kullanılarak yersel fotogrametri yöntemiyle çekilen görüntü üzerinden detay çıkarımı yapılarak restorasyon çalışmalarına katkı sağlanması amaçlanmıștır. Yazılım olarak MATLAB programının içerisinde bulunan görüntü işleme kütüphanesinden faydalanılmıştır. Bu çalışma dört aşamadan meydana gelmektedir. Bunlar; (I) Ön işleme, (II) bölütleme, (III) morfoloji, (IV) detay çıkarımı aşamalarıdır.

Ön işleme aşamasında görüntünün zenginleştirilmesi, bölütleme aşamasında görüntü içerisindeki nesnenin görüntü arka planından ayrılması, morfoloji aşamasında morfolojik operatörlerin uygulanması son olarak, detay çıkarımı aşamasında ise türev tabanlı Sobel ve Prewitt kenar algılama operatörleri, Log kenar operatörü ve Canny kenar operatörü ele alınmıştır. Orijinal görüntü ve elde edilen sonuç görüntüsü değerlendirilmiş olup görüntümüze uygulanan kenar algılama operatörlerinin birbirlerine göre avantaj ve dezavantajları belirtilmiştir.

Anahtar Kelimeler: Dijital görüntü işleme, Bölütleme, Görüntü zenginleştirme, Kenar algılama operatörleri

\section{An Application On Feature Extraction By Using Edge Detection And Morphology Operators}

\begin{abstract}
Through with the improvements in computer technology, digital image processing methods have found different and wide application areas in terrestrial photogrammetry studies. Applications of terrestrial photogrammetry, it is important for the improvement and enrichment of images of historical monuments, the preservation, the documentation of the cultural heritage and the transfer to the next generations in a healthy way. In this study, it is aimed to contribute to restoration studies by using digital image processing techniques to extract feature from image taken by terrestrial photogrammetry method. As the software, the image processing library included in the MATLAB program has been used.

The proposed method consists of four major steps: (i) Pre-processing and enhancing of image, (ii) separating foreground and background regions of an image, (iii) Morphology operators, (1v) applying derivative based Sobel, Prewitt, Laplacian of Gauss and Canny edge filters for feature extraction. The original image and the result image have been evaluated and the advantages and disadvantages of the edge detection operators which is applied to the image that are compared to each other are indicated.
\end{abstract}

Keywords: Digital image processing, segmentation, image enhancement, edge detection operators

* Sorumlu Yazar 


\section{GÍRİŞ}

Yersel fotogrametri, günümüzde restorasyon çalışmaları için vazgeçilmez bir yöntem haline gelmiştir. Yersel fotogrametri uygulamalarının büyük bir kısmını mimarlık fotogrametrisi kapsar. Bu çalışmalar tarihi eserlerin restorasyon çalışmalarında kullanılan rölövelerin hazırlanması için yapılmaktadır. Klasik yöntemlere nazaran fotogrametrik çalışmalar hem zaman kazandırdığı hem de istenilen konumsal doğruluğu vermesi sebebiyle uygulanabilecek en iyi teknoloji olarak görülmektedir (Avşar 2006). Fotogrametrinin kullanım alanlarının artması ile birlikte teknolojideki gelişmelere paralel olarak, görüntü işleme teknikleri ile görüntüler üzerinden çeşitli işlemler yapılabilmektedir. Dijital görüntüler üzerinden bilgi çıkarımı çalışılacak bölgedeki detayın karakteristiğine göre değişkenlik göstermektedir. Görüntüleri kaydeden cihazların görüntüyü hatalı bir şekilde elde etmeleri veya gölge vb. çevresel koşullar gibi olumsuzluklardan kaynaklanan gürültüler, görüntü işleme yöntemleri uygulanarak minimum seviyeye düşürülebilmektedir. Görüntü zenginleştirmede amaç görüntü içerisindeki bazı ayrıntıları ortaya çıarmak veya görüntü içerisindeki istenmeyen gürültüleri yok edilmesini sağlamak ve görüntünün yorumlanabilirliğini arttırmak için kullanılmaktadır. Bu çalışma kapsamında 3x3 ve $5 \times 5$ boyutunda çekirdek matrisleri kullanılmış olup yüksek ve alçak geçirgenli filtreler görüntü üzerine uygulanmıştır. Detay çıkarımı için görüntü işleme teknikleri içerisinde kenar algılama yöntemleri en bilinen yöntemlerdendir (Nixon ve Aguado 2012). Kenar algılama yöntemleri arasında zamanla konu ile ilgili farklı yaklaşımlar sunulmuştur. İlk olarak gradyan tabanlı Sobel, ve Prewitt kenar algılama yöntemleriydi. $\mathrm{Bu}$ yöntemler, birinci türeve dayalı, bir noktanın komşu pikselleri ile arasındaki kısmi türevlerin sayısal yaklaşımını kullanır. İkinci türev temelli olan LOG filtresi ise daha ileri bir analiz içerir. İlk olarak Marr ve Hildreth

tarafindan önerildi. $\mathrm{Bu}$ yöntem görüntüye gauss filtresi geçirilerek laplasını hesaplamaya dayanır(Gonzalez vd. 2002).
Dijital görüntü işleme teknikleri kullanılarak yersel fotogrametri yöntemiyle çekilen görüntü üzerinden detay çıkarımı yapılarak restorasyon çalışmalarına katkı sağlanması amaçlanmıştır. $\quad \mathrm{Bu}$ çalışmadaki görüntü üzerinden Matlab programı ile görüntü zenginleştirme yöntemlerinden görüntü keskinleştirme filtreleri geçirilmiştir. Yeni elde edilen görüntü üzerinden eşikleme yöntemi uygulanmıştır. Eşikleme öncesinde görüntü histogramından her bir gri ton seviyesinin görüntüde bulunma sıklığına bakılmıştır. Sonrasında eşikleme yöntemleri uygulanması ile görüntü arka planından ayrılmaya çalışılmış olup uygun eşik aralığı, morfoloji ve kenar algılama operatörleri uygulanarak tartışılmıştır.

\section{YÖNTEM}

\section{1. Çalıșma Görüntüsü}

Çalışmada kullanılan görüntü JPEG formatında olup, 210x648 piksel boyutunda ve gri seviyeli bir görüntüdür. İşlemler MATLAB programında gerçekleştirilmiştir. Şekil 1'de çalışmanın akış diyagramı gösterilmiştir.

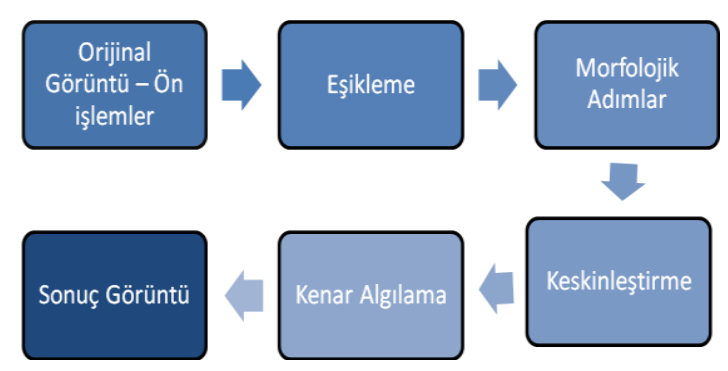

Şekil 1. Çalışmanın Akış Diagramı 


\section{2. Ön İșlemler}

Histogram, bir görüntüdeki farklı yoğunluk değerindeki piksel sayısını gösteren bir grafiktir (Gonzalez vd.2002). Çalışmada ilk olarak orijinal gri seviyeli görüntünün histogramı çıkarılarak görüntü hakkında bilgi çıkarılması sağlanmıştır (Şekil2). Histogram ile gri seviyeli bir görüntünün [0-255] aralığındaki yoğunluk değerleri ve görüntünün gri değerdeki piksel sayılarının bulunma sıklığı hakkında bilgi edinilir. Yatay eksen gri değer aralığını, düşey eksen o gri değerdeki piksel sayısını ifade eder( Gonzalez vd. 2002). Görüntüde orjine doğru gidildikçe koyu alana ait piksellerin sayısının azaldığ görülmektedir.
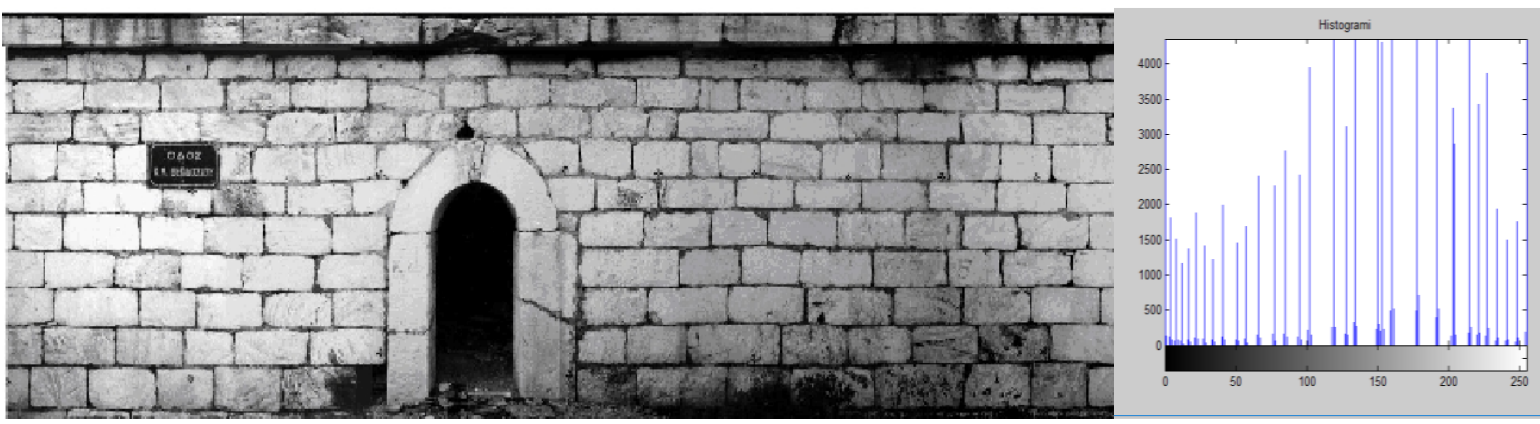

Şekil 2. Gri Seviyeli Görüntü ve Histogramı

Çalışmadaki görüntünün kontrast dağılımını iyileştirmek için histogram eşitleme yöntemine başvurulmuştur (Şekil3). Histogram eşitlemesinin başvurulmasının nedeni normal dağılımdaki aydınlık ve karanlık kısımların piksel yoğunluğunu dağıtmaya çalışmaktır. Histogram eşitlemesi, kontrastı artırmak için kullanılan bir yöntem olup görüntünün yoğunluk değerlerini tüm aralıklara yayar. Histogram eşitleme ile görüntüdeki bu yoğunluk değerleri normalize edilerek görüntüdeki karanlık ve parlaklık seviyeleri için düzgün bir dağılım sunmaktadır (Abubakar 2012 ve Shaikh vd.2014).

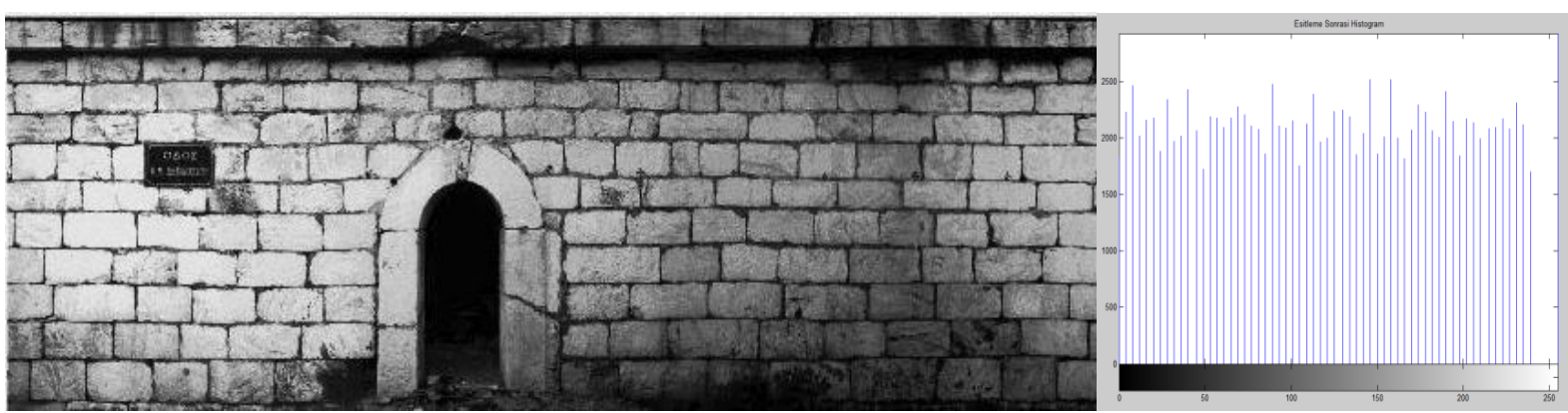

Şekil 3. Histogram Eşitlemesi Sonrası Oluşan Görüntü ve Histogramı

Şekil 1. Çalışmanın Akış Diagramı

Dijital görüntü işleme teknikleri kullanılarak görüntüden bilgi çıkarımı için en çok kullanılan teknikler arasında eşikleme yöntemleri girmektedir. Eşikleme, görüntü bölütlemesi için en basit yaklaşımlardandır.
Eşikleme yönteminin temel mantığı görüntüde bulunan nesne ile görüntü arka planını farklı yoğunluk değerlerine bağlı olarak ayırmaktır (Niea vd.2017). 


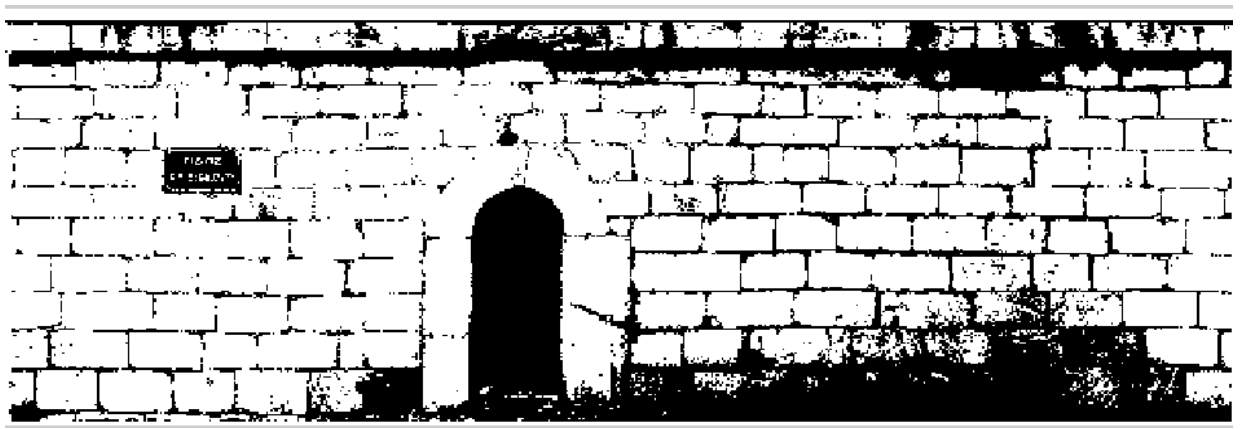

Şekil 4. Eşik Değeri 0.4 Olan İkili Görüntü

Eşik değeri, eşikleme yöntemleri arasından otsu eşik yöntemine göre belirlenmiştir. Otsu eşik yöntemi histogram bazlı bir yöntemdir. $\mathrm{Bu}$ yöntem istatiksel ayırma analizinde yaygın olarak kullanılan sinıflar aras1 varyans1 maksimum yaparak çalışır. Gri seviyeli bir görüntü nesne ve arka plan olmak üzere iki sinıfa ayrılır. Eşik değer, nesne ve arka planın her bir piksel grubu içerisindeki varyansın en küçük, nesne ve arka planın her bir piksel grubu arasındaki varyansın en büyük olacak şekilde belirlenir ( Otsu. 1975). Görüntümüzdeki eşik değer varyansına bağ $l_{1}$ olarak bu görüntüye en uygun 0.4 belirlenmiştir.

Şekil 4 'teki görüntümüzün aynı olmayan gri seviyeli nesne ve arka planından oluştuğu görülmüştür. $\mathrm{Bu}$ durumda, belli bir eşik değerin altında çıkan görüntünün bazı yerlerinde doğru bir bölütlemenin olmadığına rastlanılmıştır. Sonraki aşamada eşikleme yönteminin ayırt edemediği detaylar için matematiksel morfoloji yöntemlerinden faydalanılmıştır.

\subsection{Matematiksel Morfoloji}

Matematiksel morfoloji görüntü analizlerinde sıkça kullanılan ve araştırılan yöntemlerden biri haline gelmiştir. Matematiksel morfoloji görüntüde nesne ile arka planı ayırt edebilmek için matematiksel prensipleri kullanır. Matematiksel morfoloji görüntüdeki nesnenin yapısal özelliklerine dayanır (Serra 1986).

\subsubsection{Morfoloji operatörleri}

Bir $A \quad(x, y)$ gri seviyeli görüntüsü ile morfolojik yapıtaşı elemanı $B(u, v)$ matrisinin aşınma ve genişleme operatörleri (1) ve (2) eşitliğindeki gibi ifade edilir (Serra 1986).

$A \Theta B=\min _{\mathrm{u}, \mathrm{v}}\{A(x+u, y+v)-B(u, v)\}$

$A \oplus B=\max _{u, v}\{A(x-u, y-v)+B(u, v)\}$

Aşınma operatörüyle nesnede aşınma meydana gelir yani görüntüdeki nesneyi inceltir ya da küçültür. Genişleme operatörü ise aşınma operatörünün tam tersi rol oynar. Görüntü üzerindeki nesneyi kalınlaştırır ya da büyütür. Açma operatöründe ise morfolojik yap1 taşı elemanı ile aşındırılmış görüntünün genişletilmesi işlemidir. Kapama operatörü ise bu işlemin tam tersidir. Morfolojik yapı taşı elemanı ile genişletilmiş görüntünün aşındırılması işlemidir. Açma ve kapama operatörleri (3) ve (4) eşitliğindeki gibi ifade edilir (Bai vd.2017, Acar vd.2009, Abid Hasan vd.2016).

$$
\begin{aligned}
& A o B=(A \Theta B) \oplus B \\
& A \cdot B=(A \oplus B) \Theta B
\end{aligned}
$$

Yapıtaşı elemanı uygulanmak istenen görüntüye göre farklı boyut ve şekillerde olabilir. En çok kullanılan yapı taşı elemanları kare, dikdörtgen ve dairedir (URL1). Görüntümüzde $3 \times 3$ lük kare yapıtaşı elemanı kullanılmıştır. Yap1 taşı elemanının daha büyük olması halinde görüntüdeki bazı hatların yok olmasına neden olacaktır. Uygulamada ikili görüntü haline dönüştürülen görüntüdeki farklı bölgeler arasındaki ayırt edilemeyen küçük noktaları kaldırmak için aşınma işleminden geçirildi. Şekil 5 'te aşınma sonucunda oluşan görüntü gösterilmiştir. 


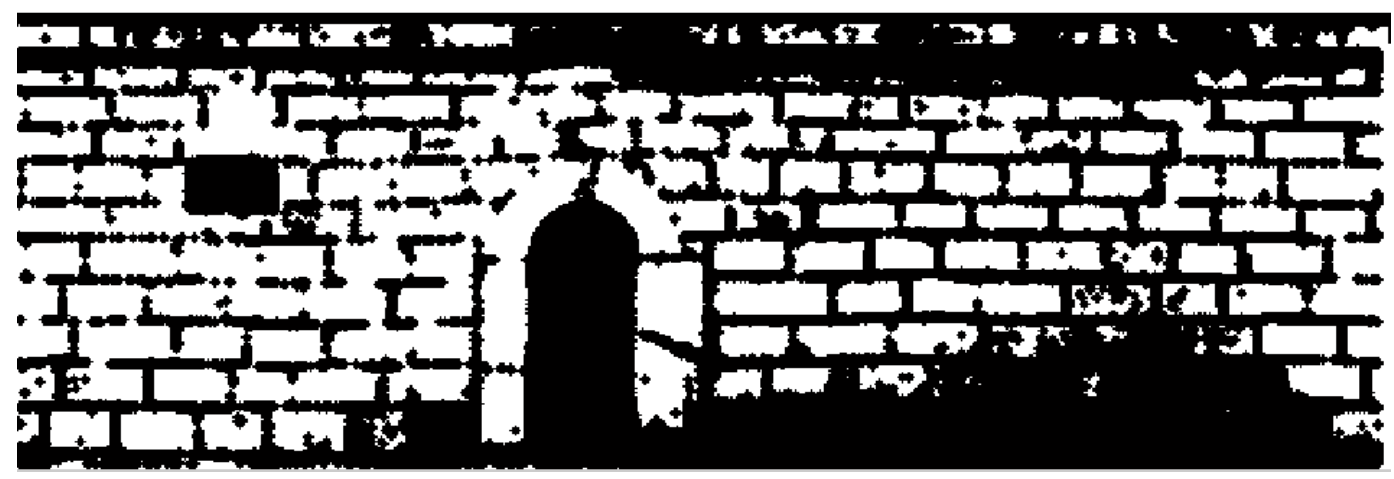

Şekil 5. Aşınma İşlemi Sonucunda Oluşan Binari Görüntü

Görüntünün aşınmaya uğradıktan sonra kalan bölgeler, genişletme işlemine tabi tutularak açma işlemi (Şekil 6) gerçekleştirilmiştir.
Sekil 6'da açma ișlemi ile nesnenin dıș hatları yumuşatılmış olup küçük çıkıntılar giderilmiştir.

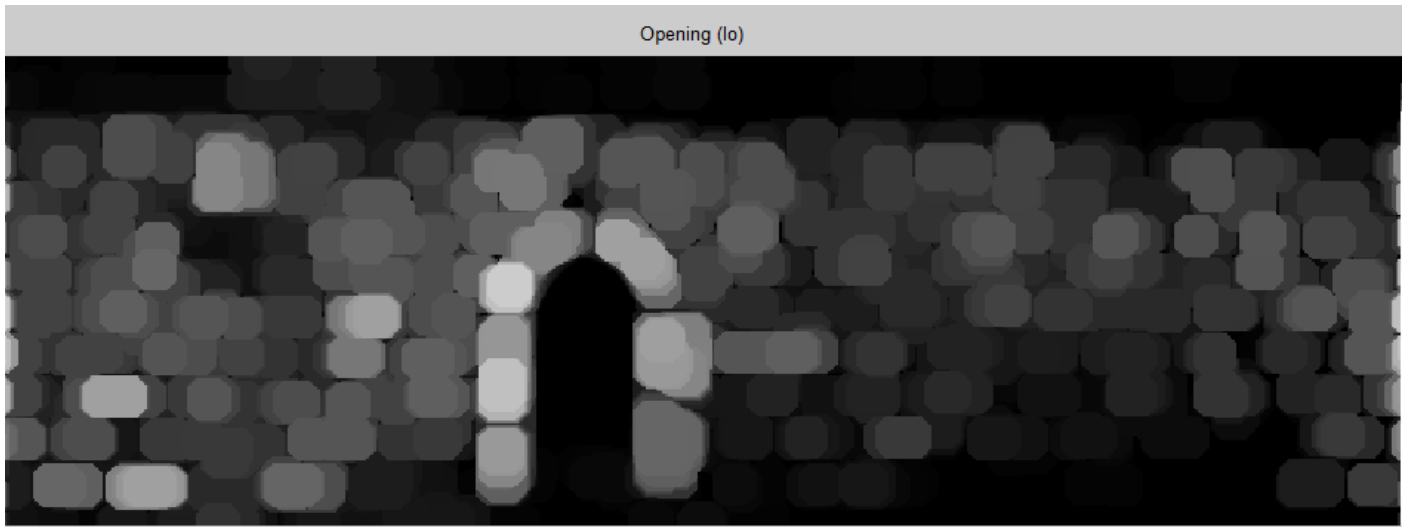

Şekil 6. Açma İşlemi Sonucunda Oluşan Görüntü

Görüntü üzerinden genişleme işleminin ardından aşınma işleminin yapılmasıyla kapama işlemi gerçekleşmiş olur. Şekil 7'de görüntü gösterilmiștir. Kapama işlemi ile görüntümüz içersindeki yakın boşluklar kapanmış olup hatlar daha belirginleşmiştir.

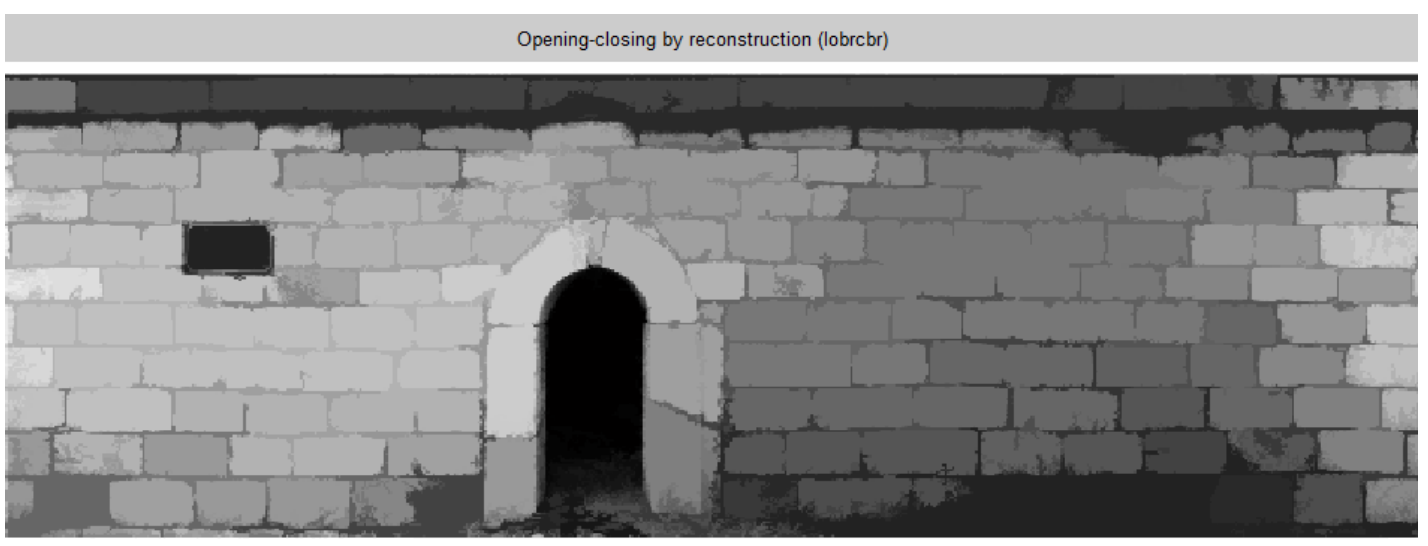

Şekil 7. Açma Kapama İşlemi Sonucunda Oluşan Görüntü 
Açma kapama yöntemi sonucunda oluşan görüntü üzerinden keskinleştirme filtresi olan unsharp filtresi geçirilmiştir. $\mathrm{Bu}$ sayede bulanık olan görüntüdeki hatlar belirginleştirilmeye çalışılmıştır (Şekil 8). Unsharp filtresinin temelinde yumuşatılmış olan görüntü, orijinal görüntüden çıkartılır.
Elde edilen fark maske olarak adlandırılır. $\mathrm{Bu}$ maske orijinal görüntüye eklenince yeni oluşan görüntü, unsharp filtresi uygulanmış olan görüntüdür. Alfa parametresi, maskeleme için kullanılan bir standart sapmadır. Alfa parametresinin farklı değerleri için farklı keskinleştirilmiş görüntüler elde edilir (Singh. 2011)

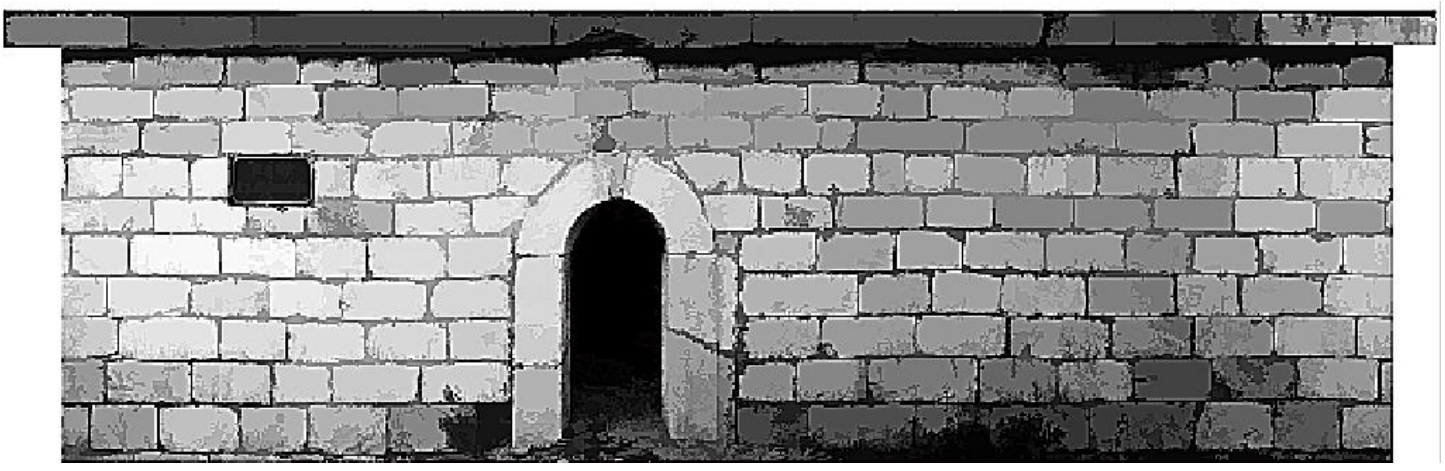

Şekil 8. Morfolojik İşlemler Sonucunda Oluşan Görüntü Üzerinden Unsharp Filtresi Geçirilmiş Hali

\section{Kenar Algilama}

Kenar algilama yöntemi, bir görüntüdeki keskin süreksizlikleri tanımlayarak görüntünün gri seviyelerindeki ani değişiklikleri belirlemeye çalışan yöntemdir. Gradyan metodu ile görüntünün birinci türevindeki en yüksek ve en düşük olduğu yerleri aranarak kenarlar saptanır(Shrivakshan vd.2012). Bu çalışmada Prewitt ve Sobel gradyanının Gx ve Gy yönünde oluşan görüntüleri şekil 9' da gösterilmiştir.

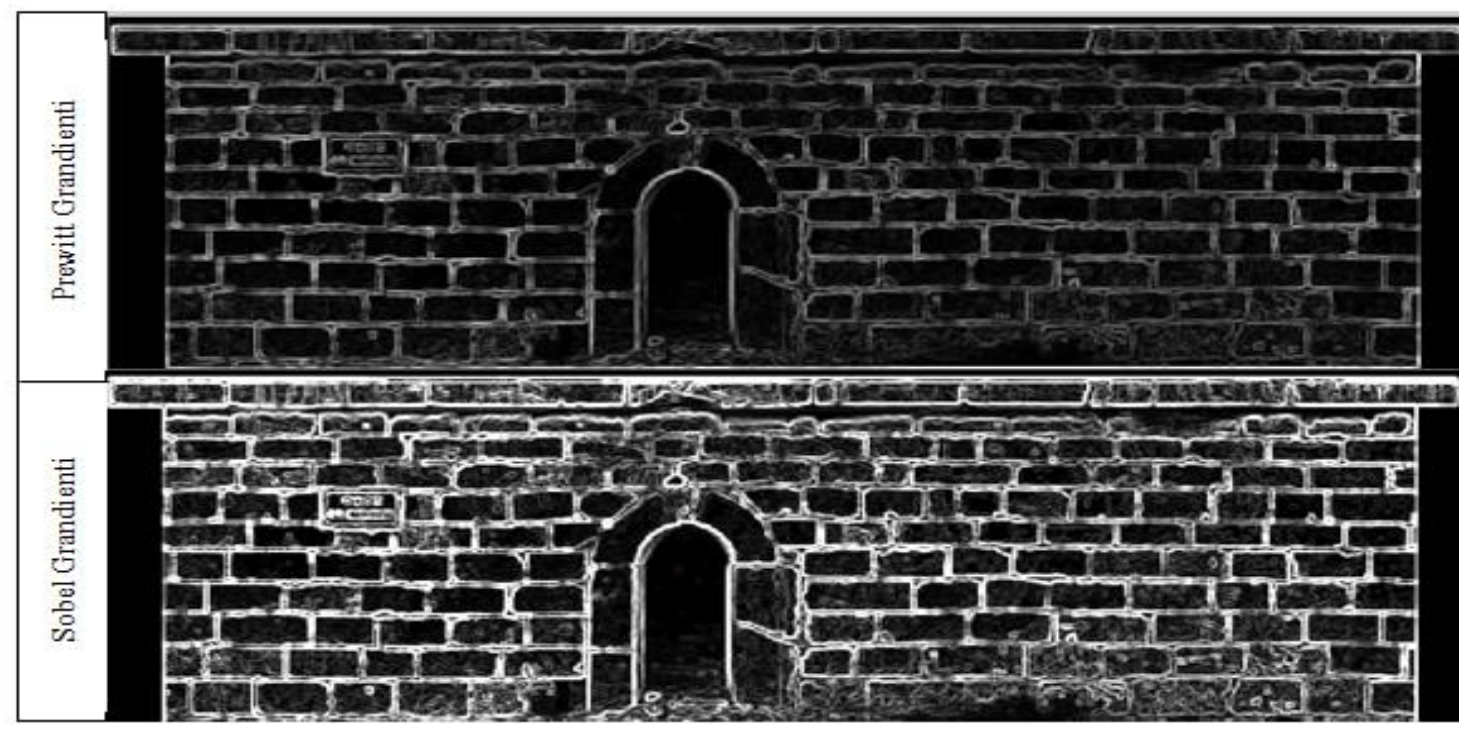

Şekil 9. Prewitt ve Sobel Gradyanının $G_{x}+G_{y}$ Yönünde Oluşan Görüntüleri 
Sobel ve Prewitt kenar algilama yöntemleri yatay ve düşey yönde kesinlikleri yakalar. Canny kenar algilama algoritmasında görüntü Gauss süzgeci ile yumuşatılır. Gradyan genliği hesaplanır. Gradyan genlik, görüntüye maksimum olmayanı baskılama uygulayarak istenmeyen ayrıntılardan ayıklar. Gaussun laplası biçimi olarak adlandırılan Log kenar algılama yöntemi ise iki boyutlu Gauss fonksiyonu ile görüntü katlama işlemine dayanır. Görüntüdeki gürültü hassasiyeti $\alpha$ parametresine göre değişecektir.
Alfa $(\alpha)$ parametresinin küçük değerleri için gürültü hassasiyeti artacak, büyük değerleri için ise gürültü hassasiyeti azalırken görüntüdeki bulanıklaşmada artış olacaktır (Gonzalez vd. 2002 ). Bu çalışmanın asıl amac1 olan görüntüdeki detaylar, kenar algılama yöntemleri ile saptanmaya çalışılmıştır. $\mathrm{Bu}$ çalışmada I. Türeve dayalı kenar belirleme metotlarından Prewitt, Sobel ve Canny kenar algılama, II. Türeve dayalı kenar algılama metotlarından Gauss'un laplası (LOG) kenar algilama yöntemleri uygulanmıştır. Bunun sonucunda oluşan görüntüler şekil 10 ve şekil 11'de gösterilmiştir.

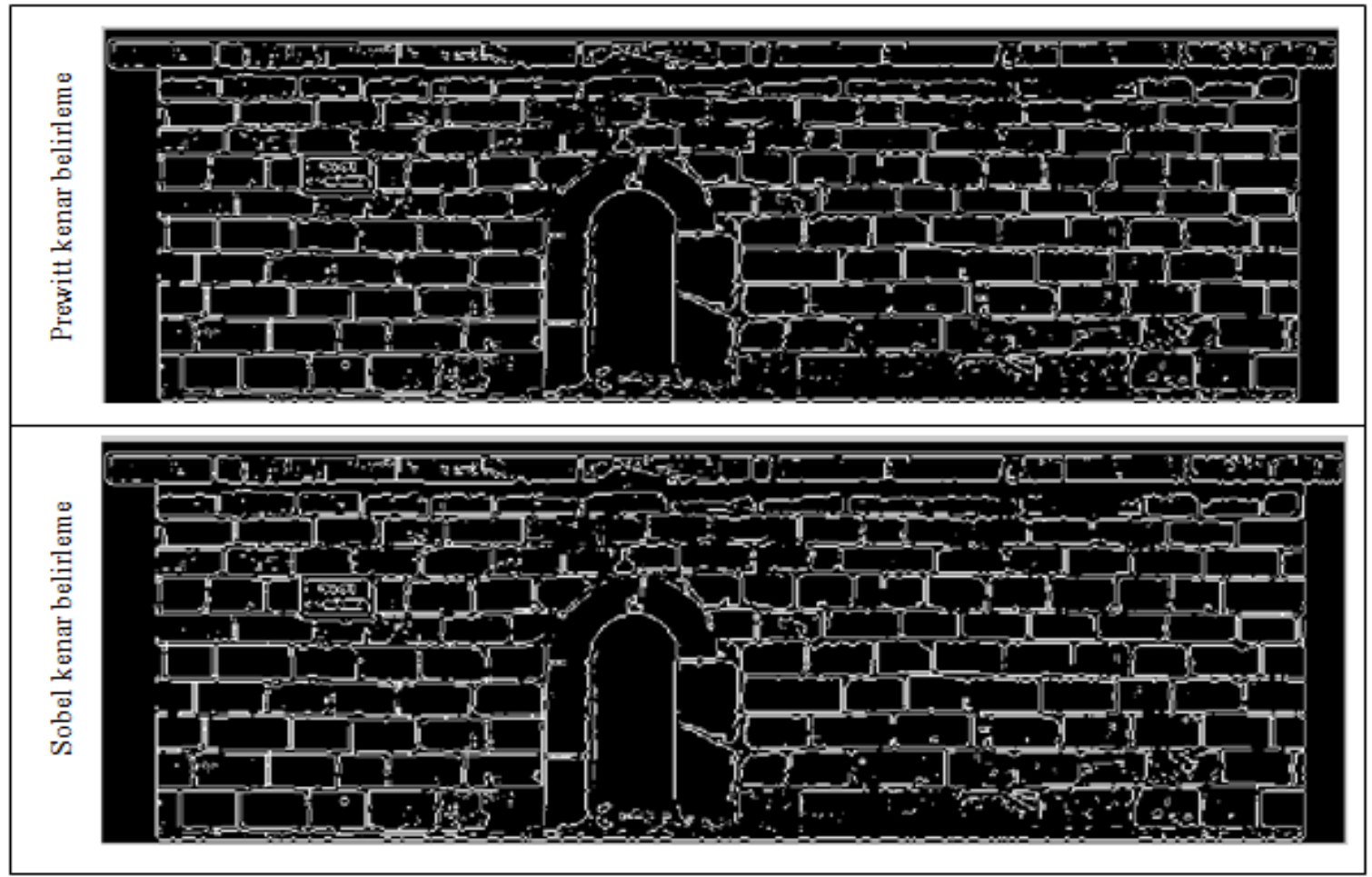

Şekil 10. Prewitt ve Sobel Kenar Algılama Algoritmaları Uygulanmış Görüntüler 


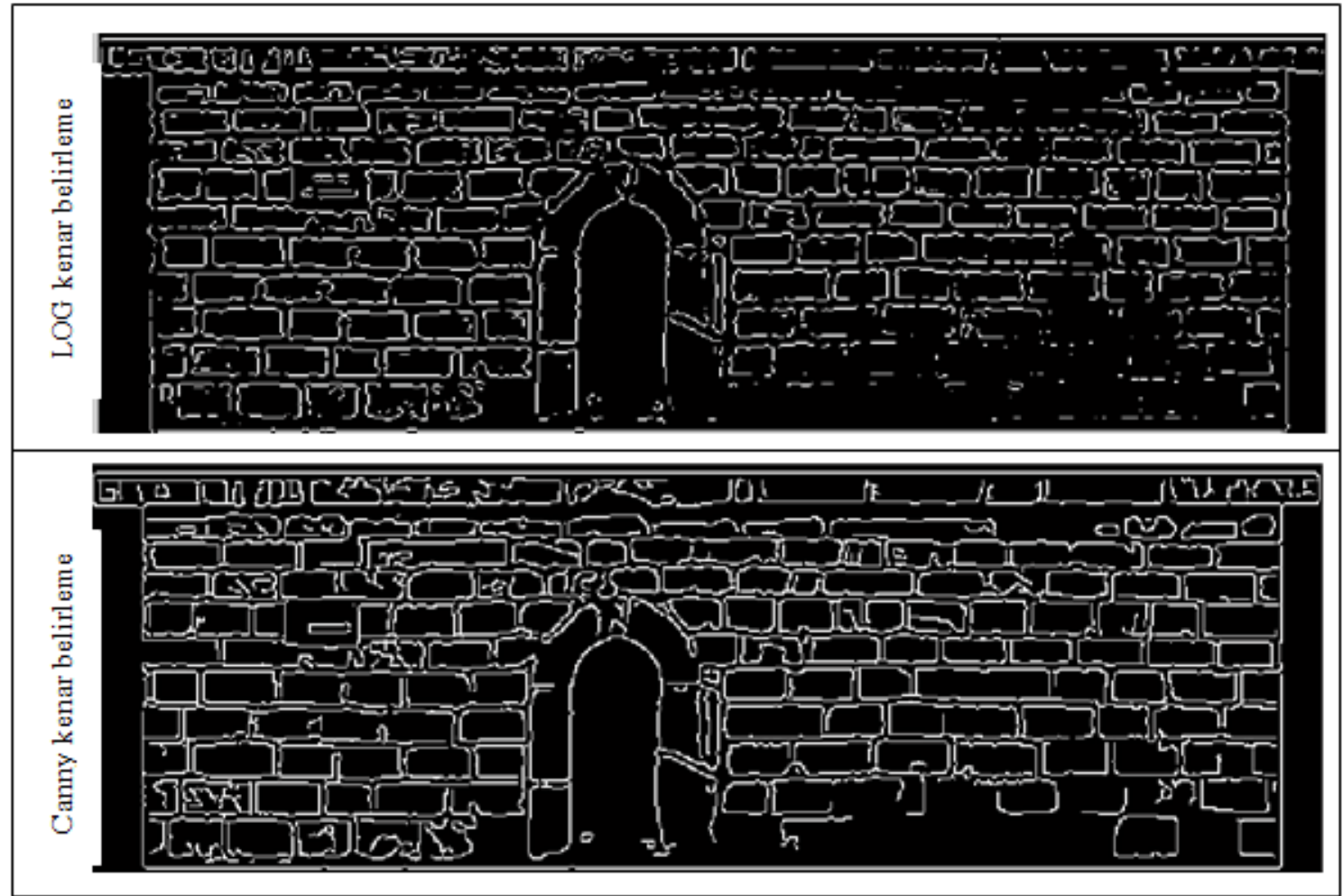

Şekil 11. LOG ve Canny Kenar Algılama Algoritmaları Uygulanmış Görüntüler

\section{SONUÇLAR ve TARTIŞMA}

Kenar algılama yöntemi görüntüdeki nesnenin detaylarının çıkarılmasında ilk adımdır. Bu çalışmada gri seviyeli görüntü üzerinden görüntü işleme teknikleri kullanılarak detayların ç̧ıarılması sağlanmaya çalışılmıştır. Çalışmada yazııım olarak Matlab programlama dili kullanılmıştır. Görüntü üzerinden ön işlemler ve morfolojik yöntemlerden sonra gradient tabanlı ve laplace tabanlı kenar algılama operatörleri uygulanmıştır.

Morfolojik işlemlerden sonra görüntü üzerinden görüntünün kalitesinin arttırmak için $3 \times 3$ boyutunda standart sapmas $1(\alpha) 0.5$ seçilen unsharp filtresi geçirilmiştir. Görüntü üzerindeki nesne ve arka planı ayırmak için kullanılan eşik değer, otsu eşik yöntemine göre bulunmuştur. Çalışmada kullandığımız görüntümüzde eşikleme yöntemi yeterli olmayıp morfolojik yöntemler ve kenar algılama operatörlerinden faydalanılmıştır. $\mathrm{Bu}$ çalışmada uygulanan kenar algılama yöntemlerinden biri olan Sobel ile Prewitt'in 3x3'lük boyuttaki işlecindeki sonuçların birbirine yakın sonuçlar verdiği görülmüştür. Uygulanan kenar algılama operatörlerinin ürettikleri sonuçlar arasından en iyi sonuç veren Canny kenar algılama operatörüdür. Görüntü üzerindeki gölge ve yosunlaşmanın etkisinden kaynaklı olumsuzluklardan dolayı bazı yerlerde detaylar tam olarak çıkarılamamıștır. Buna paralel olarak her görüntünün üzerinde çeşitli olumsuz koşullar olmakla birlikte bu görüntülere uygulanacak işlemler çeşitlilik arz etmektedir. Bundan ötürü eşik değer seçilirken farklı eşik değer yöntemleri, farklı parametre değerlerine bağl1 olarak uygulanan görüntü zenginleştirme yöntemleri, morfolojide kullanılan farklı yapıtaşları ve kenar detaylarının çıkarımı için uygulanan farklı kenar algılama operatörleri kullanılabilmektedir. Uygulanan bu yöntemlerin hepsinin birbirine göre artıları ve eksik yanlarının olmasıyla birlikte elde edilen sonuçlar optimum düzeydedir. 


\section{KAYNAKÇA}

Abid Hasan, M.S., ve Ko, K. (2016) Depth edge detection by image- based smoothing and morphological operations, Journal of Computational Design and Engineering sf. 191-197

Abubakar, F. M. (2012) Image Enhancement using Histogram Equalization and Spatial Filtering, International Journal of Science and Research (IJSR)

Acar, U., ve Bayram, B. (2009) Morfolojik Görüntü Süzgeçleri İle İkonos Görüntülerinden Otomatik Bina Çıkarımı, TMMOB Harita ve Kadastro Mühendisleri Odası 12. Türkiye Harita Bilimsel ve Teknik Kurultayı, Ankara

Avşar, E. Ö. (2006). Tarihi köprülerin dijital fotogrametri tekniği yardımıyla modellenmesi, Yüksek Lisans Tezi, İstanbul Teknik Üniversitesi, İstanbul

Bai, X., Liu,H. (2017) Edge enhanced morphology for infrared image analysis, Infrared Physics \& Technology 80 sf. 44-57

Gonzalez, R.C. ve Woods, R.E. (2002). Digital Image Processing, 3rd Edition, Prentice Hall.

Niea, F., Zhangb, P., Lia J., Din, D. (2017) A novel generalized entropy and its application in image thresholding, Signal Processing, pp.23-34

Nixon, M. ve Aguado, A. (2012) Feature Extraction and Image Processing for Computer Vision, 3rd Edition

Otsu, N. (1975). A Threshold Selection Method from Gray-Level Histograms, IEEE Transactions on Systems, Man, and Cybernetics, pp. 62-66.

Serra, J. (1986) Introduction to Mathematical Morphology, Computer Vision, Graphics, and image Processing pp. 283-305

Shaikh, M. A., ve Sayyad S.B. (2014) Color image enhancement filtering techniques for agricultural domain using Matlab, ISPRS TC VIII International Symposium

Shrivakshan, G.T., Chandrasekar, C. (2012) A Comparison of various Edge Detection Techniques used in Image Processing, IJCSI International Journal of Computer Science Vol. 9, Issue 5, No 1, 1694-0814

URL1 Image Processing Learning Recourses, http://homepages.inf.ed.ac.uk/rbf/HIPR2/ 